\title{
Transformações urbanas no sudeste do Pará e os impactos recentes trazidos pelas
}

\section{fazendas de soja}

\author{
Urban transformations in Southeast Pará and the recent impacts brought by soy farms \\ Transformaciones urbanas en el sureste de Pará y los recientes impactos de las granjas de soja
}

Recebido: 19/07/2021 | Revisado: 25/07/2021 | Aceito: 29/07/2021 | Publicado: 05/08/2021

Sérgio Ricardo Siani

ORCID: https://orcid.org/0000-0002-2182-8873 Universidade Federal do Sul e Sudeste do Pará, Brasil E-mail: sergiosiani@unifesspa.edu.br

Carmino Hayashi

ORCID: https://orcid.org/0000-0002-4709-947X Universidade Federal de Alfenas, Brasil

E-mail: hayashi@terra.com.br

\begin{abstract}
Resumo
Atualmente, o Brasil é uma potência agrícola, sendo maior produtor de soja com o uso de inovação e de uma tecnologia de ponta conseguiu inclusive ultrapassar os Estados Unidos na última safra. A região Norte do Brasil não é uma região tradicional na produção de soja, por consequência o mesmo acontece com o Estado do Pará. Contudo, um fenômeno vem acontecendo. Aos poucos a área rural que sempre teve criação de gado bovino de leite e de corte vem perdendo espaço para a plantação de soja. São vários os possíveis impactos, que a chegada das fazendas de soja têm trazido para a comunidade local de Rondon do Pará, gerando críticas positivas e negativas. Assim, o presente trabalho tem como objetivo mapear e discutir quais atores foram mais impactados pelas transformações trazidos pelas fazendas de soja à cidade de Rondon do Pará-PA. A metodologia adotada para fazer a pesquisa, foi qualitativa, com triangulação de dados na coleta, utilizando-se de observação participante, análise documental e entrevistas semiestruturadas. Conclui-se, entre outras coisas, que os produtores de soja trouxeram um impacto direto na concentração da propriedade de terras e renda. O poder público agora tem um papel ainda mais importante, de intermediar e criar políticas públicas que possibilitem a desigualdade. A mão de obra direta, menos escolarizada, teve menor impacto, contudo desenvolveu-se uma quantidade considerável de fornecedores na cidade para atender a demanda da soja.
\end{abstract}

Palavras-chave: Soja; Produtores de soja; Pará; Transformações urbanas.

\begin{abstract}
Currently, Brazil is an agricultural power, being the largest producer of soy with the use of innovation and cuttingedge technology, it even managed to surpass the United States in the last harvest. The Northern region of Brazil is not a traditional region in soy production, therefore the State of Pará is not either. However, a phenomenon has been taking place. Little by little, the rural area, which has always had dairy and beef cattle raising, is losing space to soy plantations. There are several possible impacts that the arrival of soy farms has brought to the local community of Rondon do Pará, generating positive and negative criticism. Thus, this work aims to map and discuss which actors were most impacted by the transformations brought by soy farms to the city of Rondon do Pará-PA. The methodology adopted to carry out the research was qualitative, with triangulation of data in the collection, using participant observation, document analysis and semi-structured interviews. It is concluded, among other things, that soy producers had a direct impact on the concentration of land ownership and income. Public authorities now have an even more important role, to mediate and create public policies that make inequality possible. Direct labor, less educated, had less impact, however a considerable number of suppliers were developed in the city to meet the demand for soy.
\end{abstract}

Keywords: Soybean; Soybean producers; Pará; Urban transformations.

\section{Resumen}

Actualmente, Brasil es una potencia agrícola, siendo el mayor productor de soja con el uso de innovación y tecnología de punta, incluso logró superar a Estados Unidos en la última cosecha. La región norte de Brasil no es una región tradicional en la producción de soja, por lo tanto, el estado de Pará tampoco lo es. Sin embargo, se está produciendo un fenómeno. Poco a poco, la zona rural, que siempre ha tenido ganadería lechera y de carne, va perdiendo espacio ante las plantaciones de soja. Son varios los posibles impactos que la llegada de las fincas de soja ha traído a la comunidad local de Rondon do Pará, generando críticas positivas y negativas. Así, este trabajo tiene como objetivo mapear y discutir qué actores fueron más impactados por las transformaciones que trajeron las fincas de soja a la 
ciudad de Rondon do Pará-PA. La metodología adoptada para realizar la investigación fue cualitativa, con triangulación de datos en la recolección, utilizando observación participante, análisis documental y entrevistas semiestructuradas. Se concluye, entre otras cosas, que los productores de soja incidieron directamente en la concentración de la propiedad de la tierra y los ingresos. Las autoridades públicas tienen ahora un papel aún más importante, mediar y crear políticas públicas que hagan posible la desigualdad. La mano de obra directa, menos educada, tuvo menos impacto, sin embargo se desarrolló un número considerable de proveedores en la ciudad para satisfacer la demanda de soja.

Palabras clave: Soja; Productores de soja; Pará; Transformaciones urbanas.

\section{Introdução}

Conforme dados da Empresa Brasileira de Pesquisa Agropecuária - EMBRAPA, a produção de soja representou 53,4\% do total de grãos no país no tocante a safra 2017/2018, contudo ela está concentrada em duas regiões do Brasil, a Região Centro-Oeste e Sul, e dos 27 estados do país, os maiores produtores estão respectivamente apenas em cinco estados, Mato Grosso, Paraná, Rio Grande do Sul, Goiás e Mato Grosso do Sul (Hirakuri, 2020).

A região Norte do Brasil não é uma região tradicional na produção de soja, por consequência o Estado do Pará também não é. Contudo, um fenômeno vem acontecendo. Aos poucos a área rural que sempre teve criação de gado bovino de leite e de corte vem perdendo espaço para a plantação de soja. Nesse contexto, as cidades tem sofrido grandes transformações, e este trabalho pretende abordar essas transformações.

Uma das cidades que tem vivido grandes transformações em função da chegada das fazendas de soja, é Rondon do Pará (Figura 1), que é um município do Sudeste do Estado do Pará, com 52.803 habitantes (Ibge, 2021).

Figura 1 - Foto aérea de Rondon do Pará - PA

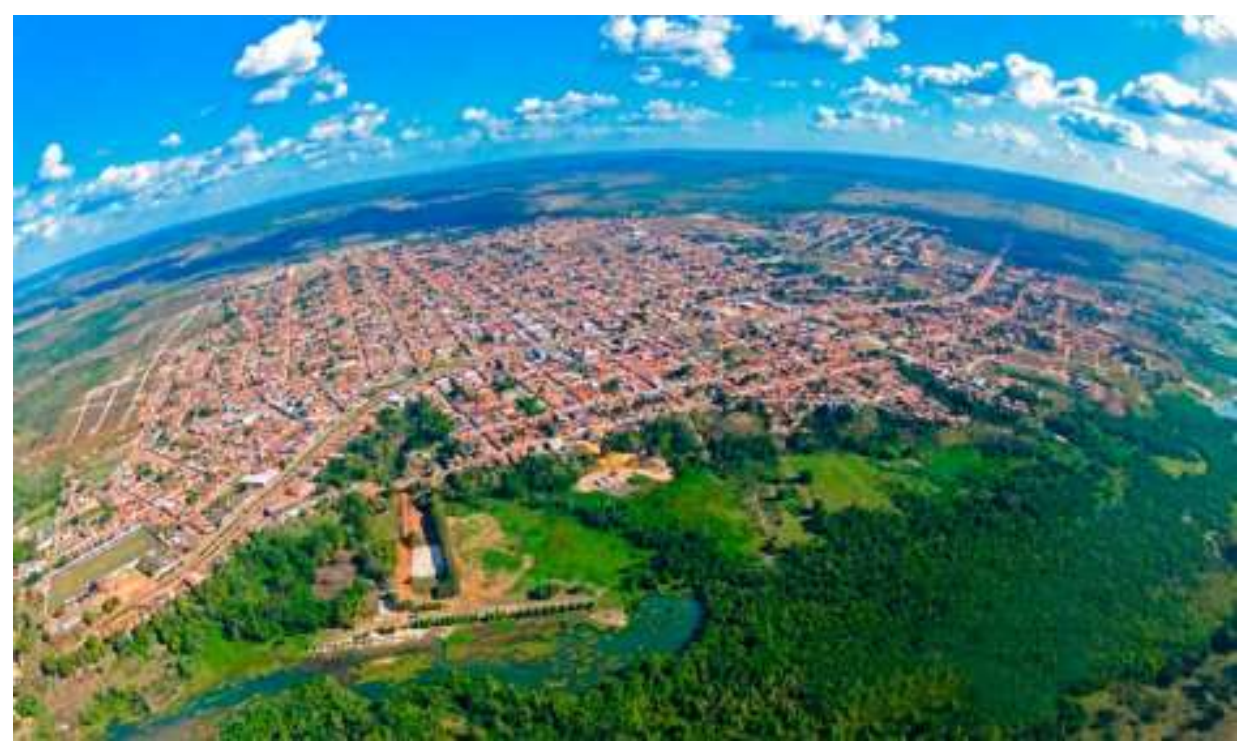

Fonte: ZEDUDU (2021).

Foto: Ricardo Tavares D’almeida

Até a poucos anos atrás ela se mantinha economicamente pela criação de gado de leite e de corte, mas como a advento da demanda por soja da China e pela proximidade com o Estado de Tocantins (maior produtor de soja da Região) vem sofrendo grande transformação de seus pastos, onde a plantação de soja para a exportação vem ampliando seus domínios e transformando a maneira de viver da população urbana e rural.

Vale destacar que atualmente o Brasil é uma potência agrícola, destacando-se na produção de grãos, e o emprego de inovação tecnológica, sendo que é o maior produtor de soja, tendo inclusive ultrapassado, os Estados Unidos, com uma 
produção na safra 2020/2021 ao redor de 135 milhões de toneladas, com 38 milhões de hectares plantados (Embrapa soja, 2021). O estado do Pará é o segundo maior produtor de soja da região Norte, atrás somente do Tocantins (Conab, 2021).

O município de Rondon do Pará contribui para esta produção segundo a Secretaria da Agricultura e Pecuária de Rondon do Pará, num total de 135 fazendas licenciadas com uma área de 34.180 hectares. São vários os possíveis impactos, que a chegada das fazendas de soja tem trazido para a comunidade local de Rondon do Pará, gerando críticas positivas e negativas.

Assim, o presente trabalho tem como objetivo mapear e discutir quais atores foram mais impactados pelas transformações trazidos pelas fazendas de soja à cidade de Rondon do Pará-PA.

Montoya et al. (2019) lembram que para atender a uma demanda cada vez maior por soja no mercado mundial é necessário cada dia mais terras para o plantio, contudo essa prática tem trazido inúmeras críticas, pois essa expansão quase sempre é feita sem seguir um padrão de sustentabilidade.

Vale destacar que a realização deste trabalho se justifica, pois a Organização das Nações Unidas ao criar os dezessete objetivos para o desenvolvimento sustentável (ODS), conhecida como agenda 2030, tem como um dos desafios apresentados, o ODS 11 que é a tornar as cidades e comunidades sustentáveis (Onu, 2021), e ainda, nesse momento, várias iniciativas para se obter um crescimento inclusivo, com redução da pobreza, pensando em meios sustentáveis, já começaram a ser discutidas em cidades de todo o mundo (Steel et al., 2020).

\subsection{O Mercado da soja}

Historicamente a soja é uma planta leguminosa cultivada na China Central há cinco mil anos, sendo que passou a se espalhar pela Ásia há três mil anos, onde passou a ser consumida como alimento. Nos Estados Unidos ela foi introduzida comercialmente apenas no século XX, e a partir daí ela teve rápida expansão da produção. No Brasil o primeiro grão chegou em 1882 no Estado da Bahia (Sanches, et al., 2004).

Contudo, os fazendeiros brasileiros começaram a produzir a soja no final da década de 1960, quando ela passou a ser vista como um produto que tinha valor comercial, pois perceberam que era possível fazer farelo para a produção de suínos e aves (de Souza Paiva et al., 2019; Montoya et al., 2019).

As primeiras plantações de soja no Brasil eram desenvolvidas em conjunto com a plantação de trigo, pois os produtores usavam o mesmo equipamento e o cultivo acontecia em épocas diferentes do ano, então sempre se via a produção de soja e trigo acopladas na década de 1960 (Sorj, 2008).

No início da década de 1970 a soja ainda era uma curiosidade no país, sem expressão nem no mercado interno e menos ainda no mercado internacional, era incipiente. Naquela época o Brasil era importador de alimentos, pois a produção causava muitos impactos ambientais negativos. Contudo, com a crise cambial colocando em risco a segurança alimentar, o Governo Federal na época, já imaginando que o país poderia ser competitivo nessa área implementou medidas que viriam mudar completamente a história do agronegócio brasileiro, principalmente o investimento em desenvolvimento de tecnologia em apoio a modernização do setor (Gazzoni, 2013).

Ainda naquela época foi possível uma expansão da produção visto que já se apontava um mercado favorável a compra da soja, o governo federal da época criou novos incentivos a agricultura, que já se desenhava um desenvolvimento da cadeia produtiva, com a implantação de tecnologias, produção de sementes, modernas técnicas de manejo, o que fez essa combinação de fatores um próspero futuro para a soja (de Cassia Campos, 2010; Hirakuri \& Lazzarotto, 2014; Montaya et al., 2019).

Mas foi na década de 1980 que a produção de soja começou a ter uma nova perspectiva a de substituição de algumas atividades agropecuárias, em especial da bovinocultura de corte e também das fazendas que cultivavam a plantação de arroz, 
visto que tais atividades demandavam de baixo uso de tecnologia e baixo valor agregado, diferente dos níveis de eficiência e estabilidade de produção que a soja já dava demonstração (Hirakuri \& Lazzarotto, 2014).

Entre os anos de 1980 e 1985 notou-se que a produção da soja em grandes propriedades vinha aumentando muito. A produção da soja dava sinais que seria uma cultura que exigiria grande escala dos produtores, e que produzi-la em pequenas propriedades era desaconselhável (de Souza Paiva et al., 2019).

Ainda, segundo Hirakuri e Lazzarotto (2014) foi nas últimas décadas, do século XXI, que a produção da soja no Brasil tem se destacado pelo seu crescimento expressivo. Segundo eles (2014) tal crescimento pode ser atribuído a vários fatores como o desenvolvimento de um mercado internacional comprador de soja robusto, a consolidação da soja como um importante componente vegetal para é usado para atender a demanda de produtos para animais e a expansão do uso de modernas tecnologias por parte dos produtores de soja. Assim foi possível a expansão da soja no Brasil e no mundo.

Na década de 2000, Hirakuri (2020) destaca o grande crescimento do plantio de soja no Brasil, graças a alguns fatores que combinados fez o sucesso atual da soja, entre eles o aumento do poder de compra da população de grande parte dos países emergentes aliado ao fato do mercado internacional ter se tornado ainda mais robusto demandando uma quantidade maior de produtos agrícolas especialmente o que são usados na proteína animal, como o caso da soja.

Esse encontro da demanda e da oferta é regulada pela Bolsa de Chicago - CBOT (Chicago Board of Trade), referencial em preço de mercadorias (Hirakuri, 2020). Bem que na década de 2000 houve um aumento expressivo de equipamentos desenvolvidos com novas tecnologias para serem usados na produção da soja, que permitiu que houvesse uma ampliação na produção (Hirakuri e Lazzaroto, 2014).

Ainda que a área ocupada pela soja seja de apenas $4 \%$ do território brasileiro, ela se consolidou como o principal produto agrícola do país. Ainda vale destacar que segundo a Embrapa a distribuição do solo brasileiro é dividido em $66 \%$ é coberto por vegetação ou é uma área de preservação permanente, chamada APP, representando 554 milhões de hectares, 23\% são pastagens, usadas na alimentação de gado, representando 198 milhões de hectares, 8\% são utilizados em agricultura, para a produção de grãos, como o milho e a soja, representando 60 milhões de hectares e ainda $4 \%$ destinados a urbanização e outros usos (Aprosoja, 2021).

Aprosoja (2021) relata que dos $8 \%$ do território destinado a produção de grãos, a soja ocupa 3,5\% ou seja aproximadamente 33 milhões de hectares e projeta que esse número só tende a aumentar e que na safra que compreende os anos de 2024 e 2025 pode subir sua produção em 50\% podendo ocupar até 5\% do território nacional.

Especula-se que como as regiões Sul e Centro Oeste tem pouco espaço para desenvolver maior numero de lavouras de soja, os fazendeiros tem procura outras regiões do país para desenvolver ainda mais seus negócios. Esse movimento é chamado na literatura como "alargamento do território da soja" que se dá pela entrada da soja em regiões até então não exploradas, especialmente onde tradicionalmente se cria bovinos, conforme demonstrado nas imagens 1 e 2 o Estado do Pará tem sentido o impacto dessa expansão.

Silva e Anjos (2020) relatam que além das áreas que criavam bovinos, ovinos e equinos, a pecuária familiar também vem sentido a expansão da soja, que tradicionalmente se opõem a essa cultura mais tecnológica.

Segue os gráficos com a série história da área plantada de soja no estado do Pará (Grafico 1) e a expansão da produção da soja no mesmo estado (Gráfico 2). 
Gráfico 1 - Série história de área plantada com soja no Estado do Pará.

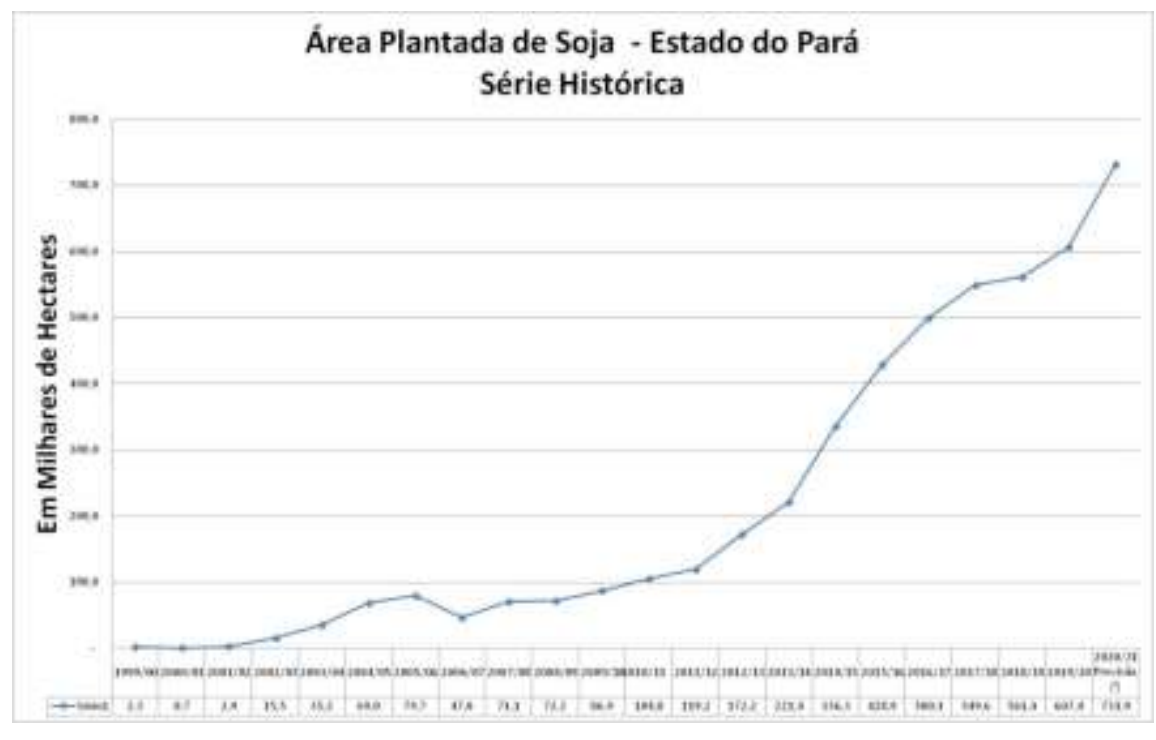

Fonte: Autores com dados do CONAB (2021).

Pode-se verificar que na safra de 1999 e 2000 o estado do Pará tinha apenas 3 mil hectares plantados com soja, passando para a safra 2010 e 2011 para mais de 100 mil hectares plantados e em 2020 e 2021 com 731 mil hectares pantados.

A expansão da cultura da soja, hoje vai além da região Centro-Oeste do Brasil, está ruma ao Norte e Nordeste do país, e está baseada na tecnologia, preocupada principalmente com a sustentabilidade da sua produção (Gazzoni, 2013).

De certo, como disse Escher e Wilkinson (2019) houve uma explosão da expasnão da área plantada no Brasil, sendo que um dos principais fatores foi o "boom" das commodities que elevou o preço médio da saca de soja em $232 \%$, que passou de US\$ 13,88 em 2006 para US\$ 35,09 em 2012. Outra vantagem que o brasil é o fato que o escoamento da safra brasileira se dá na entressafra americana.

Ainda por cima o Brasil se tornou a grande esperança de aumento da produção de soja mundial, já que ele possui áreas intactas que permitem que se multiplique por três a sua produção sem a destruição da floresta amazônica. São alvos dos produtores de soja áreas como o cerrado da região Centro-oeste, do Nordes te e também do Meio Norte, e todo o estado do Maranhão, com a expectativa de incorporação de mais 106 milhões de hectares de terras (Escher \& Wilkinson, 2019).

Abaixo o Gráfico 2 mostra a evolução histórica da produção de soja no estado do Pará.

Gráfico 2 - Série história da produção de soja no Estado do Pará.

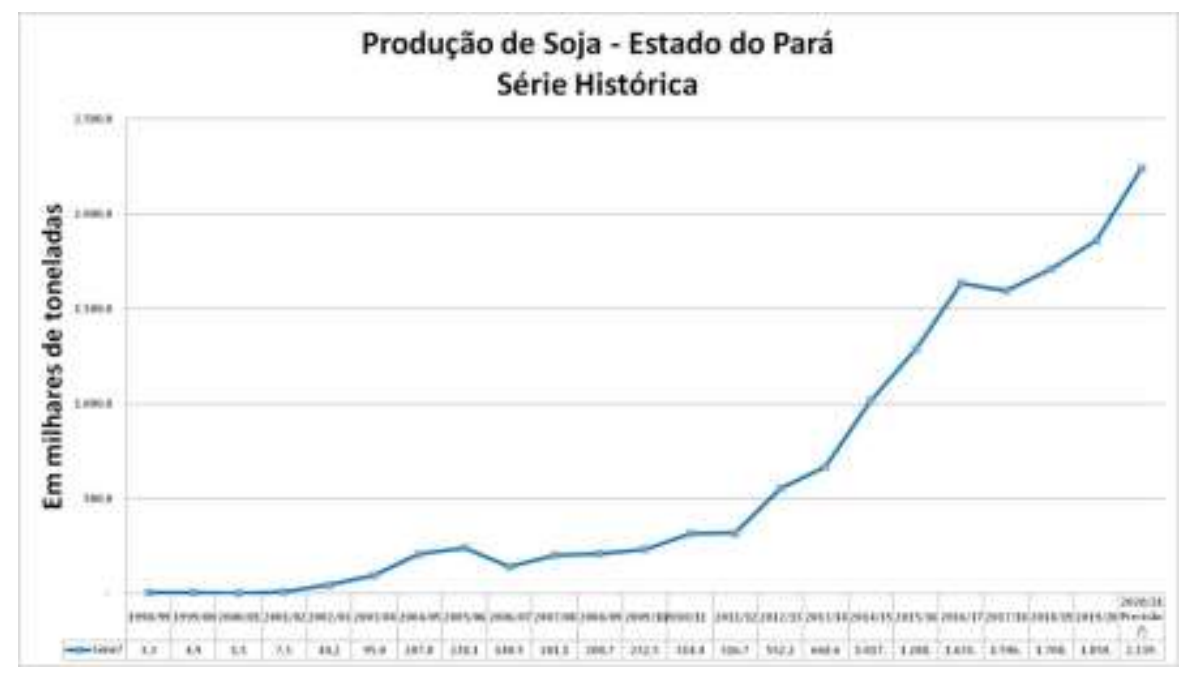

Fonte: Autores com dados do CONAB (2021). 
Pode-se verificar que na década de 1998 e 1999 o estado do Pará tinha apenas 3,3 mil toneladas produzidas de soja, passando em 2011 e 2012 para 314,4 mil toneladas produzidas e já na safra de 2020 e 2021 com 2,2 milhões de toneladas de soja.

Mas também o que ajudou a esse aumento de produção é a utilização da soja como óleo além de ser usada para a produção de proteína animal, e esses dois mercados são sólidos. Outro fator que merece atenção é a cadeia produtiva da soja e a alta liquidez do grão no mercado internacional (Hirakuri \& Lazzarotto, 2014).

Os autores (2014) relatam o destino da produção dos grãos é direcionado ao setor industrial, sendo que aproximadamente $89 \%$ é destinado ao processo de esmagamento enquanto o destino a alimentação humana corresponde algo em torno de 5\%. Por fim relatam que o consumo de soja na China, que é o principal destino das exportações brasileiras é de 6,5 vezes maior que a sua produção interna, o que gera grande dependência de importação do produto.

Por fim, sumariamente, a cultura da soja, é um grande exemplo do agronegócio moderno do Brasil, alicerçado em políticas publicas que incentivaram seu desenvolvimento, uso de tecnologia de ponta, com empresários de alto nível empresarial, com organizações atuantes (sindicatos, associações e cooperativas). Ainda que o "Custo Brasil" seja um obstáculo, a produção da soja conseguiu êxito em vencê-lo. Um caso de êxito dos últimos 40 anos de investimentos (Gazzoni, 2013).

\subsection{Transformações urbanas}

Transformações urbanas podem ser entendidas semanticamente como o processo e o resultado para atingir uma nova configuração de uma cidade, ao passo que "transição" deve ser entendida apenas como o processo dessa transformação. O termo "transformação" é usado num campo mais diverso e permite que exista um diálogo mais amplo e interdisciplinar (Wolfram et al., 2016).

É através das transformações urbanas que as cidades podem oferecer contribuições para a sustentabilidade e resiliencia a nível local e global, e serve também para compreender novas funções urbanas e as interações e suas implicações para a população. A chave dessa discussão é colocar as cidades num palco e olhar para as necessidades e oportunidades criadas em direção a sustentabilidade, sem perder de vista que as cidades tem experimentado mudanças constantes e processos de mudança incomparáveis no mundo contemporâneo (Hölscher \& Frantzeskaki, 2021).

Dentre as transformações ocorridas nos territórios e municípios pela nova, pode-se destacar: a necessidade de se reestruturar a agropecuária e a indústria, a expansão do setor de serviços e também do comércio, a localização das industrias, a necessidade de expansão das empresas que trabalham com tecnologia, o aumento de trabalho intelectual, as novas formas de consumo, e por fim a busca por uma melhor condição de vida, ligado aos movimentos migratórios (Elias \& Pequeno, 2007).

O discurso sobre o futuro urbano, envolve uma problemática envolvendo o colapso em função do desenvolvimento, sendo que, como tal apresenta três principais desafios que são a instabilidade econômica, a degradação do meio ambiente e a desigualdade social (McPhearson et al. 2016), e os governos municipais e globais tem que enfrentar cada vez mais esses desafios que inclui ainda a redução da pobreza, o desemprego e as mudanças climáticas (Steel, 2020).

Nas ultimas duas décadas os governos municipais principalmente nos Estados unidos tentam incorporar a temática ambiental na organização das cidades, já que a sustentabilidade passou a estar no centro do planejamento (Lang, 2014), e devemos pensar em cidades que possam acomodar a todos (Lenden, 2014), em busca de uma transformação urbana sustentável (Wolfram et al., 2016).

Na perspectiva de analisar as cidades brasileiras, três pontos devem ser repensados: a) a necessidade de se criar um pacto que discuta os limites territoriais, já que existe um extrapolamento dos limites físicos das cidades, b) dada a importância do solo urbano, olhar para as demandas sociais, já que naturalmente eles vem aumentando e dificilmente atendidas, c) 
Problemas ambientais, econômicos e de mobilidade já que eles vão impactar ao acesso a itens essenciais da população como vagas nas escolas, nas creches e nos hospitais (Lima \& Silveira, 2018).

O Banco Mundial (World Bank, 2015) ao discutir o papel das cidades no mundo destacam que as cidades contribuem com 70\% a $80 \%$ do PIB global e conjuntamente com o crescimento econômico, a prosperidade e a urbanização ajudam na redução da pobreza, gerando novas oportunidades para a população, além de frequetemente aumentarem a renda das pessoas.

Ainda no relatório do Banco mundial (World Bank, 2015) há um destaque para os governos que estão dando as cidades, visto que os países estão se urbanizando rapidamente e dá um destaque especial para a experiência que o Brasil teve em tornar suas cidades mais inclusivas, e como lidou com a inclusão das áreas urbanas e destaca (p. 74): "as políticas e programas de desenvolvimento urbano do Brasil têm sido exemplares em muitos aspectos"

O crescimento estável da economia na década de 1990, deu inicio a políticas publicas focadas em três eixos: o social, o econômico e o espacial. Algumas ações do governo federal fizeram com que as cidades ganhassem autonomia, entre elas, pode-se destacar: O programa "Bolsa Familia" que faz transferência de renda para famílias mais pobres, o microcrédito para empresas fornecido pelos bancos, incentivo ao microempreendedor, o aumento real do salário mínimo, a urbanização das favelas pelo Programa Nacional de Aceleração do Crescimento - PAC, e o subsídio habitacional as famílias de baixa renda chamado "Minha Casa Minha Vida" (World Bank, 2015).

Assim, discutir as cidades é um fator crítico e necessário, pois temos que olhar para o futuro da população e dos centros urbanos, pois é ela que liga uma rede institucional técnica e cientifica, publico e privado, ligando as organizações empresariais às soluções criativas e inovadoras, olhando para a inclusão (Weiss et al., 2017).

O espaço rural da cidade não deve ser considerado como algo apartado da cidade, visto que ele está presente no seu crescimento, e está presente na cultura dela, na forma que as pessoas compreendem e vivem na cidade (Gillen, 2016).

Já quase não existe mais fronteira entre a zona rural e urbana, as diferenças culturais, de modo de vida e empreendimentos urbanos e rurais vem se transformando e ficando cada vez mais tênue (Steel, 2020), mas foi a globalização que deixou o território desorganizado, pois agora ele passa a ser reelaborado para atender a demanda agrícola globalizada (Elias \& Pequeno, 2007).

O agronegócio contribui significativamente para a transformação das cidades, visto que é de lá que ele vai tirar a mão de obra, materiais e serviços necessários ao seu negócio. Assim, quanto mais se intensiva o capitalismo no campo, mais urbana é a regulamentação e sua administração, tornando mais complexa as relações entre campo e cidade, o que implica numa significativa transformação urbana do território, principalmente nas pequenas e médias, acirrando as desigualdades. (Elias \& Pequeno, 2007).

A lógica de mercado prevalece cada vez mais, e como impulsionador de desenvolvimento está o Estado, que tem um papel crucial na busca do entendimento das questões sociais e do bem estar da população, pois o mercado pode ser criador de riqueza, mas também um grande produtor de desigualdades sociais (Vitte, 2010; Castilho et al., 2016).

Portanto, a transição urbanas de muitas cidades brasileiras ainda acontecem de forma abrupta e não tão harmoniosa, sendo que a parte mais difícil fica para a camada mais pobre da população, ainda que ela seja a parte majoritária da população, e uma engrenagem muito importante para o desenvolvimento nacional, é muito raro que ela veja seu lugar numa expansão urbana, e ai pode estar a raíz de grandes problemas das cidades brasileiras (Martine \& McGranahan, 2010).

\section{Metodologia}

A presente pesquisa se enquadra como pesquisa aplicada, visto que ela procura resolver problemas de ordem prática e focada em interesses e solução de problemas focadas em determinada localidade (Gerhardt \& Silveira, 2009). 
Quanto à abordagem, a pesquisa caracteriza-se como qualitativa. Creswell (2010) afirma que pesquisa qualitativa é o meio pela qual busca-se entender o significado que as pessoas ou grupos atribuem a um problema social ou humano. E que durante o processo de pesquisa os dados devem ser coletados no ambiente do participante, e a análise dos dados deve ser construída partindo das particularidades para o tema geral.

Quanto aos objetivos, a pesquisa caracteriza-se como exploratória, pois tem a pretensão de deixar aquele assunto mais explícito, procurando desenvolve-lo, mas também tem a preocupação de fazer um esclarecimento, ou mesmo de alterar um conceito pré concebido (Gil, 2007).

Quanto aos procedimentos de coleta de dados, a pesquisa é documental, observação participante e entrevistas em profundidade semiestruturadas. Entende-se por entrevista individual em profundidade a técnica qualitativa que explora o entrevistado de forma estruturada, buscando informações, percepções de experientes e especialistas e intensidade nas respostas (Duarte, 2005).

Quanto ao modelo da entrevista ser semiestruturada Triviños (1987, p. 146) define: "Aquela que parte de certos questionamentos básicos, apoiados em teorias e hipóteses, que interessam à pesquisa, e que, em seguida, oferecem amplo campo de interrogativas, fruto de novas hipóteses que vão surgindo à medida que se recebem as respostas do informante".

Foram entrevistados três produtores de Soja (referidos como PRO 1, 2 e 3), um proprietário de Silo (lugar de armazenamento da soja) referido como SILO, quatro comerciantes com mais de 20 anos de comércio (referidos como MER 1 ao 4), que sentiram os impactos das mudanças trazidas pela soja, e quatro pessoas ligadas ao governo municipal (Referidos pelo código SVD 1 ao 4). Para criar as categorias e codifica-las foi utilizado o software NVIVO.

Dessa forma, então, em seguida, foi utilizado o roteiro sugerido por Carlomagno e Rocha (2016), que estabelece cinco etapas para classificação de categorias para análise, onde resumidamente: 1) Estabelece-se regras claras para inclusão e exclusão em cada categoria, 2) Verifica-se se as categorias são autoexcludentes, 3) Não deixar as categorias muito amplas, 4) Verificar se as categorias contém todos conteúdos possíveis, 5) Fazer uma classificação objetiva e com uma codificação que não tenha subjetividade.

Também foi utilizado pesquisa documental, já que tivemos que buscar junto a prefeitura, qual o número de fazendas licenciadas e junto ao Consul buscou-se a série histórica de produção da soja, tentando entender se a produção da soja estaria ganhando importância no estado do Pará.

Segundo Gil (2019) a pesquisa documental é relevante, pois permite a complementação de outros instrumentos e técnicas de coleta de dados, trazendo maior relevância ao tema de interesse. Segundo ele, a pesquisa documental possui algumas vantagens, como: ter os documentos como uma fonte rica e estável de dados, sendo também estes documentos uma fonte importante de dados em qualquer pesquisa de natureza histórica; e não exigir contato com os sujeitos da pesquisa, já que em muitos casos, o contato com os sujeitos pode ser difícil, ou até mesmo impossível, e pode conter informações prejudicadas pelas circunstâncias do contato com os mesmos.

Ainda, o principal autor esteve presente na cidade pesquisada entre Agosto de 2019 e Julho de 2020, onde pode fazer uso da observação participante. Serva e Jaime Junior (1995) explicam que essa metodologia é usada quando o pesquisador está face a face com o objeto pesquisado, e as pessoas passam a ser sujeito de um projeto de estudos.

Assim, foi possível fazer uma triangulação de dados (Figura 2), como sugere Marcondes e Brisola (2014, p. 203) "No que tange à coleta de dados, a Triangulação permite que o pesquisador possa lançar mão de três técnicas ou mais com vistas a ampliar o universo informacional em torno de seu objeto de pesquisa". 
Figura 2 - Triangulação na coleta de dados.

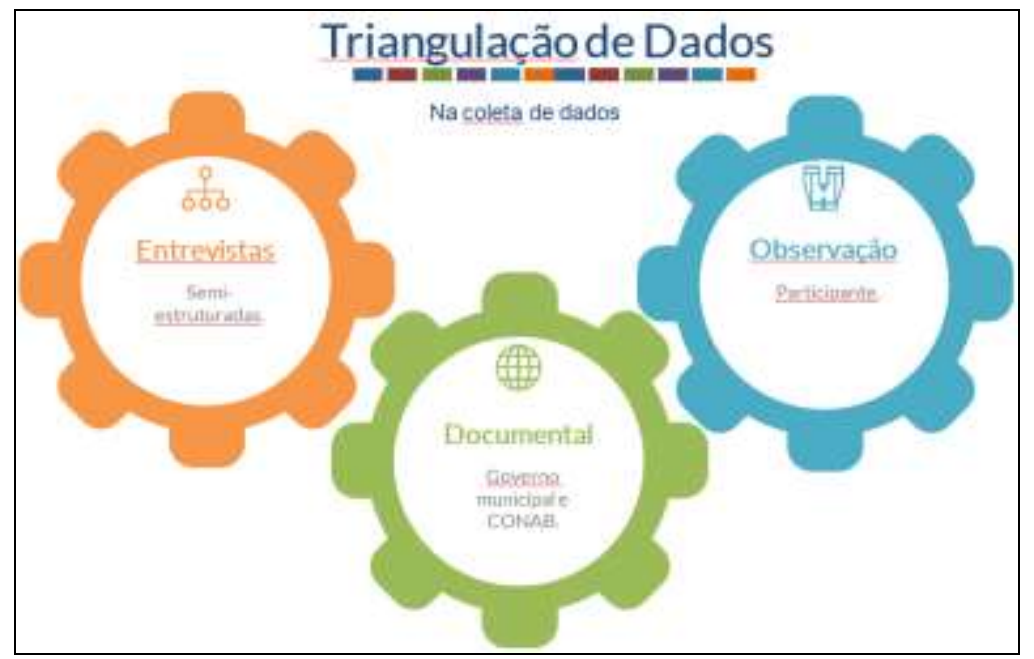

Fonte: Autores.

Com base nas entrevistas emergiu a categoria de análise "As transformações urbanas acontecidas no município de Rondon do Pará-PA", visto que esse tema era recorrente entre os entrevistados.

\section{Resultados e Discussão}

\subsection{As transformações urbanas acontecidas no município de Rondon do Pará-PA}

A principio buscou-se identificar de que maneira a cultura da soja chegou no município de Rondon do Pará, visto que ele tradicionalmente é reconhecido como um lugar dedicado a criação de bois para abate. Assim, SVD 04, que acompanhou todo esse processo de transformação pode explicar a influencia do Estado nos primeiros passos do desenvolvimento da soja, ele lembra:

A cultura da soja era uma APL (Arranjo Produtivo Local) no inicio da soja ele começou em 1995 e foi em um campo experimental, no km 56 (da rodovia 222 que liga Rondon do Pará aos municípios vizinhos) em uma área da prefeitura ou seja o poder público foi o primeiro a plantar soja no município. Era experimento né para ver se dava certo ou não, a colheita foi um sucesso e a produção foi ótima foram 20 alqueires de soja plantado nessa época daí então houve seminário em nosso município patrocinada pelo governo do estado com a comunidade local dos fazendeiros.

A cultura da soja foi desenvolvida desde seu início com incentivo do governo. O Estado brasileiro teve papel importante na criação da cadeira produtiva. Os mercados foram sendo liderados pelo Estado e nos primeiros anos, depois que o mercado já estava consolidado o Estado tem intervindo menos, mesmo assim a participação estatal continua tendo influencia via políticas agrícolas (Del Villar, et al., 2004).

Igualmente Campos (2010) explica que o mercado da soja foi desenvolvido por um duplo incentivo. Um deles foi o aumento do consumo de óleo de soja Interno e externo) e o uso da soja como matéria prima para o farelo como ração animal. O outro fator foi o a política econômica do Brasil a partir da década de 1970 de inserção no comercio internacional de commodities, sendo um dos maiores exportadores. Assim, a soja passou a ser o "carro chefe" da modernização da agricultura nacional puxada pelo Estado.

A mudança de negócio trouxe resistência. Mas com o passar do tempo a produção da soja começou a se consolidar e passou a influenciar os municípios vizinhos, além de atrair produtores de outras regiões do país. Uma outra consequência foi a valorização das terras que não tinham valor para a pecuária mas tinha muito valor para a soja, como destaca SVD 04: "no 
primeiro momento foi uma resistência dos fazendeiros porque a nossa atividade principal era a pecuária né pecuária de corte, Rondon era famosa pela pecuária de corte". Mas o governo municipal fez um trabalho de convencimento dos pecuaristas na época, que diziam: "não vou tirar o meu capim para plantar soja, jamais vou fazer isso aí, não vou, não acredito nisso!".

Ainda na fase inicial da soja no município, os terrenos com planícies extensas, não tinham muito valor, mas passaram a ter muito valor a partir de 2008 quando a produção de soja começou a ter uma escala industrial. Então a partir daí as transformações aconteceram de forma mais intensa, muitos pecuaristas começaram a arrendar suas terras para os produtores de soja, fazendo que diminuísse a oferta produtos ligados a agropecuária, como relata PRO 3 "eu diminui minhas terras para a criação de gado. Antes criava apenas bois. Agora está pouco. Dividi minha atividade entre soja e bois. Maior parte pra soja”. Da mesma forma MER 2 que é um comerciante de carne na cidade relata essa diminuição do espaço para a criação de gado “diminui a cada ano, aumentando as lavouras de soja, diminuindo as fazendas que criam gado, cada ano que passo tenho mais dificuldade em comprar carne. Eu conheço fazendas inteiras que criavam gado que hoje plantam soja". A ong WWF (de conservação global) já alertava que isso iria acontecer "no business usual, a soja continua invadindo as savanas naturais e pastos existentes, "empurrando" os criadores de gado e os pequenos fazendeiros para as florestas" (Dros, 2004, p.4).

Mas, a referida ONG, também apresenta o caminho para uma bem sucedida convivência entre todos os atores:

A implementação bem sucedida de usos alternativos do solo requer uma mudança de paradigma junto aos produtores, governos, compradores, investidores e reguladores. Os governos locais precisarão contar com o compromisso, e o apoio, de atores da cadeia de produção e marketing de soja, a fim de promover práticas mais sustentáveis. A adoção de critérios de origem do produto, e o desenvolvimento de diretrizes para os produtores, por meio de uma associação de múltiplos interessados, são complementos necessários para que as medidas legais possam reduzir os impactos negativos do setor de produção de soja, identificados em importantes ecossistemas e comunidades locais (Dros, 2004, p. 4).

Essa transição também foi sentida pelas pessoas que tinham relacionamento com os pecuaristas e agora se relacionam com os produtores de soja, como relata SVD 01, quando perguntado se tem diferença profissional entre os dois profissionais:

Tem bastante diferença sim, o sojeiro (produtor de soja) é mais técnico porque ele tá acostumado a trabalhar com um produto mais delicado, que requer mais conhecimento técnico, de como tratar o solo, já o pecuarista que é acostumado jogar capim lá no meio do pasto e o capim crescer e o gado comer, ele tem muita resistência a fazer investimentos, e o sojeiro ta acostumado a fazer grande investimento para ter retorno alto também.

Primeiro aspecto importante identificado antes de se começar a produção da soja é o rigoroso controle documental exigido ao produtor, tanto pelos órgãos reguladores, quanto pelas instituições financeiras. Como revelou PRO 2:

O primeiro passo para tá pensando em produzir a questão documental e questão ambiental da área, quem pensa em produzir, tem que olhar primeiro a questão documental, e a tem algum embargo, se a área é documentada, ai a gente pensa em investir, em produzir, porque nós não conseguimos tão pouco vender nossa produção se não tiver documentação, e falando da área principalmente a questão ambiental é importante, a gente não consegue recursos instituições financeiras se não estiver toda documentação em dia.

A dependência do agronegócio das instituições financeiras foi algo que surgiu em todas entrevistas com produtores. Por se movimentar valores altos, o negócio requer um banco parceiro, como já demonstrado o negócio da soja só vem crescendo, aqui tem uma grande oportunidade para as instituições financeiras.

$\mathrm{Na}$ verdade os bancos criam um setor dentro dele especializado em agronegócio, já que essa modalidade de negócio tem suas peculiaridades. Na cidade o principal parceiro tem tradição em trabalhar com os produtores rurais, que é o Banco do Brasil, que em sua plataforma (bb.com.br/agronegócio) destinada ao agronegócio pode ser identificada uma gama de produtos financeiros enorme, tanto pequeno, médio e grande produtor rural, além de serviços para as cooperativas e fornecedores parceiros. 
Na sequencia do processo da soja, após a fase documental, identificou-se que os produtores começam a fase da "mecanização", ou seja preparar o solo, deixando-o plano, para que não haja impedimento no momento que for passar alguma maquina por ele, conforme apresenta PRO 3 " a gente tira toco de árvores, faz as correções, faz o nivelamento do terreno, correções de erosões, curvas de níveis, essa é a parte de mecanização". O que fica demonstrado que a produção de soja tem algo nível de tecnologia empregada na produção. Aparentemente isso não teria de correlação com a transformação das cidades, mas como ficará demonstrado a seguir ter forte ligação.

Quando um novo negócio se instala em uma cidade sempre existe uma expectativa que ele traga renda e emprego para aquele local. Isto pode ser visto também na literatura, no caso já soja: “...a cadeia da soja é importante para economia brasileira, pois gera renda e emprego, e contribui para a estabilidade da macroeconômica do país por meio de seu faturamento, ajudando a amenizar o déficit da balança comercial” (Cunha \& de Melo Cruz, 2017, p. 749).

Contudo, essas duas variáveis, renda e emprego são questionadas pelos respondentes da pesquisa. Primeiro, se a produção de soja tem grande uso de tecnologia, faz pouco uso de mão de obra, como percebe SVD 1 "soja não é como canade-açucar que requer muita mão de obra, é mais técnico, com mão de obra de fora da cidade também. E também onde tem muita tecnologia tem pouca mão de obra” e SVD 2 também explica que:

A questão do emprego, a geração de emprego da soja ela gera muito pouco, contrata muita prestação de serviço sim, eles usam muito caminhão alugado para transporte da colheita para os silos para armazenar né, e eles usam também muito maquinário locado, para fazer a colheita, agora a mão de obra em si é muito pouco, muito pouco porque tudo é no maquinário né, tudo é na produção em escala Industrial, aqui tem um produtor grande aqui que até as máquinas dele são automatizadas controlável via GPS, lá no escritório dele ele controla tudo, então nem nem funcionário tinha na máquina, se ele quisesse operar sem a máquina sem operador e fazia toda a colheita lá, até a plantação dele fazia automatizada.

Mas como explicou SVD 2, os fornecedores aparecem como impacto positivo para a cidade, visto que muitos precisam se instalar no município para prestar serviços aos produtores. Nesse aspecto SILO, que é um prestador de serviços para os produtores de soja, também confirma, que mesmo que seus negócios estarem da cidade ao lado de Rondon do Pará, quando ele chegou na cidade tinha uma instituição financeira e agora tem sete, além dele empregar 70 funcionários. SVD 2 também credita aos produtores de soja a vinda de empresas fornecedoras com a Bunge e Juparaná, e a criação de empresas com Silos para armazenar a colheita.

Uma das características mais fortes do agronegócio globalizado é sua for ligação com a economia da cidade onde ele está instalado, gerando uma relação intensa entre o campo e a cidade, quase fazendo que não haja diferença entre esses dois espaços, pois as cidade vai suprir o agronegócio com mão de obra, bancos, advogados, matéria prima, máquinas e assistência técnica, aumentando a economia local (Elias \& Pequeno, 2007).

Essa economia especializada faz com que a cidade onde ela acontece e as cidades que estão a sua volta abrigue vários fornecedores de material e serviços, desde uma pequena casa de ferragens para dar manutenção as máquinas usadas na lavoura, como transnacionais concessionárias de máquinas, além de bancos, e agentes especializados como agrônomos, engenheiros e outros. O poder público acaba tendo que se moldar também ao agronegócio, o que deixa a relação do campo com a cidade mais complexa (Elias, 2011; Castilho et al., 2016).

Além disso, esse maior fluxo, faz com que aumente o trânsito entre as cidades vizinhas, e pode criar um crescimento desordenado, visível ao longo do seu sistema viário, ou mesmo pelas vias de acesso às sedes das localidades rurais (Gazzoni, 2013).

Ainda, considerando as observações realizadas, pode-se constatar um grande movimento de emigração de pessoas de Rondon do Pará para os Estados Unidos, e não há garantia que tal fato esteja diretamente relacionado com a chegada da cultura da soja na cidade, mas vale destacar que tal fato tem impacto grande na cidade, visto que ao passo que essas pessoas que 
conseguem trabalho no América do Norte recebem salário em dólar, e com a valorização dessa moeda no Brasil e o envio de dinheiro para seus familiares na cidade de origem traz impacto no comércio local. Pouca literatura se tem sobre isso, contudo em reportagem do jornal Folha de São Paulo de 24 de setembro de 2010 (Mota, 2010), a prefeitura de Rondon do Pará estimava que seis mil pessoas da cidade viviam nos Estados Unidos, um número representativo já que a cidade tem em torno de 50.000 habitantes.

Ainda se referindo as observações realizadas, percebe-se um expressivo aumento do comércio local, num momento em que o país sofre uma retração econômica em função da pandemia do Coronavírus. Esse fenômeno foi observado também por SVD, 2 e 3 e MER 1, 2 e 4. Mas foi MER 1 que destacou:

A gente percebe a chegada de muitas empresas que não são da cidade, fiquei sabendo que o banco Santander e o banco Itau estão procurando imóveis para se instalar aqui, o Chiquinho Sorvetes, que é uma rede que só tem em cidade com mais de 200 mil habitantes tá se instalando aqui (que tem 50.000 habitantes), e nos últimos meses se instalou as Lojas Americanas e Magazine Luisa (grandes redes de varejo), são lojas que a gente achou que jamais iria ver aqui, além de grandes redes de supermercado.

MER 1 relata fatos que já são realidade na cidade e outros que podem acontecer, o fato é que a cidade vive um clima de euforia no comércio local, causado pela soma de três fatores: a) O desenvolvimento de fornecedores trazidos pelo desenvolvimento da produção da soja na cidade, b) Desenvolvimento de lojas, de grandes redes de varejo admiradas pela população, que tinham que viajar para cidades maiores para adquirir seus produtos e agora pode comprar em sua própria cidade, c) Isso fez com que os comerciantes locais tivessem que fazer promoções e se reinventar para conseguir concorrer com os grandes varejistas, trazendo um benefício extra à população.

Gazzoni (2013) explica esse fenômeno, pois quando se tem uma reestruturação produtiva no agronegócio acontece uma verdadeira revolução na geografia da cidade, isso acontece porque esse negócio é globalizado, e impõe essa especialização em seu território, ou seja, quanto mais avança o agronegócio mais urbana se torna sua regulamentação, passando a ser a "cidade do agronegócio", passando a desempenhar novas funções, focando na cooperação desse novo negócio.

\section{Considerações Finais}

O presente trabalho teve como objetivo o presente trabalho tem como objetivo mapear e discutir quais atores foram mais impactados pelas transformações trazidos pelas fazendas de soja à cidade de Rondon do Pará-PA.

Pode-se perceber que a cidade não é mais a mesma depois que a cultura da soja foi implantada na cidade, houve uma transformação na cultura local, parece que a cidade se moldou as necessidades do agronegócio. Isso deixa a cidade mais vulnerável, sendo que ela fica dependente de uma monocultura, já que todo o agronegócio na cidade está baseado na produção da soja, e esta é uma commodity que tem variáveis externas ao domínio dos produtores. No tocante aos impactos trazidos sobre a população, procuramos analisar que atores tiveram maior e menor impacto.

No que tange a renda da população, a transformação está vindo por dois fenômenos que aparentemente não tem ligação. O primeiro é o desenvolvimento dos fornecedores locais, ou seja através de uma mão de obra indireta, já que para produzir as safras anuais de soja, foi desenvolvido na cidade e não região uma quantidade considerável de fornecedores especializados em atender as demandas dos produtores. O segundo impacto está acontecendo pela alta do valor do dólar no mercado interno, e já que a cidade é considerada uma das maiores emigrantes de brasileiros para os Estados Unidos, faz com que os familiares que ficam na cidade de origem recebam, ainda que pagando impostos, algum rendimento. A soma desses dois 
fatores faz a atração para a cidade de novos varejistas, e o comércio passa a se desenvolver mais, mesmo em época de crise no país, ou seja os comerciantes foram muito impactados positivamente (demonstrando na Figura 2).

Figura 3 - Transformações urbanas em Rondon do Pará.

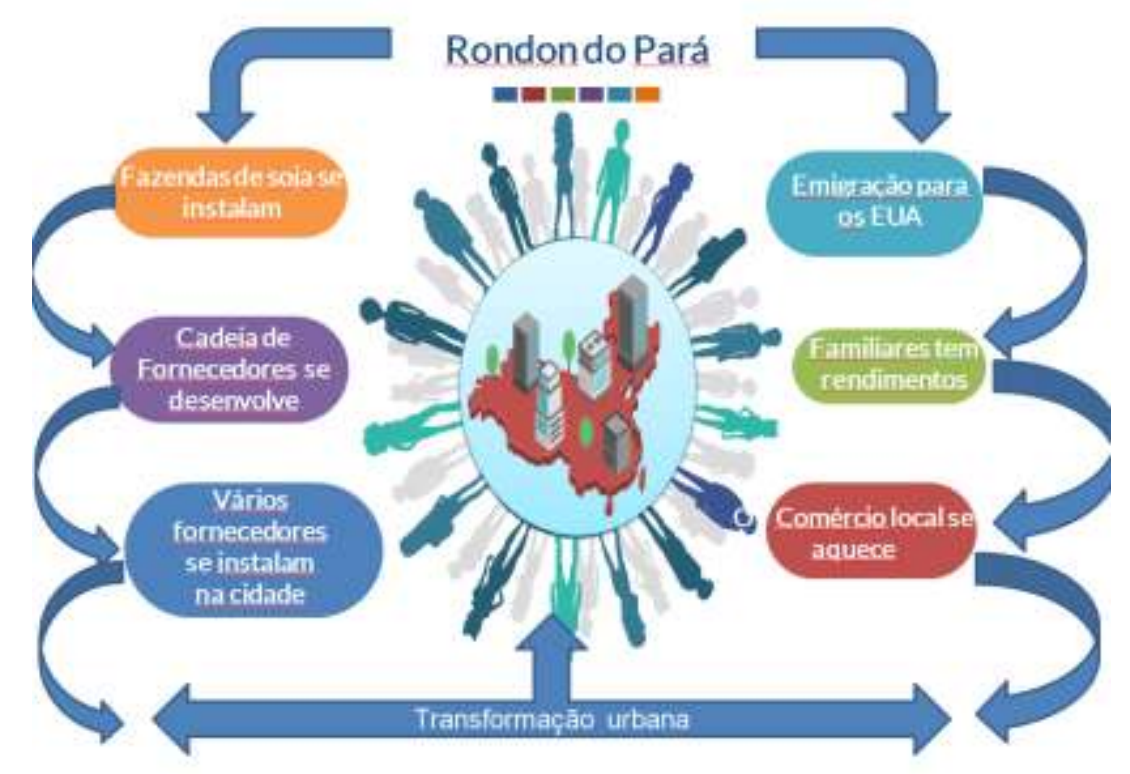

Fonte: Autores.

Outra característica importante é cada vez maior a concentração tanto de renda como de posse das terras. Ainda que em muitos casos se identificou o arrendamento de terras para o plantio da soja, também houve aquisição de terras por valores bem baixo no início, já que terras com planície não eram valorizadas na agropecuária, e posteriormente, em função da procura, aconteceu uma supervalorização das terras. Ou seja os proprietários de terras e investidores foram impactados e sofreram grandes transformações ocasionadas pela soja.

Mapeando, ainda, os atores impactos pela transformações trazidas pela produção de soja, pode-se verificar que o poder público municipal parece ganhar importância dentro deste cenário, onde as desigualdades ficam mais exacerbadas, pois cabe a ele fazer a intermediação entre os mais ricos e mais pobres e criar políticas públicas que atendam as expectativas de ambos, que claramente é uma missão difícil.

E a mão de obra mais simples, de menor conhecimento técnico, sofreu pouco impacto da soja, visto que ela se utiliza muito pouco dessa mão de obra, tendo grande dependência de mão de obra especializada, seja no plantio, ou na colheita da soja, ou seja em todo seu processo produtivo tem pouco espaço para a mão de obra menos qualificada.

Por fim, esse fenômeno de expansão da soja parece não acabar aqui, ao passo que ela se expande as relações entre seus atores fica mais complexa, e a cidade mais dependente. Como trabalho futuro sugere-se a comparação dessa região que como foi comprovado é bastante recente a chegada da produção da soja, com outras regiões que tal cultura já está desenvolvida a bem mais tempo, como é o caso do Estado do Mato Grosso, que produz soja desde a década de 1970.

\section{Referências}

Aprosoja. (2021) Associação brasileiros dos produtores de soja. https://aprosojabrasil.com.br/a-soja/ambiental/

Carlomagno, M. C., \& da Rocha, L. C. (2016). Como criar e classificar categorias para fazer análise de conteúdo: uma questão metodológica. Revista Eletrônica de Ciência Política, 7(1).

Castilho, R., Elias, D., Peixinho, D., Buhler, E. A., Pequeno, R., \& Frederico, S. (2016). Regiões do agronegócio, novas relações campo-cidade e reestruturação urbana. Revista da ANPEGE, 12(18), 265-288. 
Conab (2021). Série histórica das safras. https://www.conab.gov.br/info-agro/safras/serie-historica-das-safras?start=30

Creswell, J. W. (2010). Projeto de pesquisa: métodos qualitativo, quantitativo e misto. Bookman.

Cunha, R. C. C., \& de Melo Cruz, W. L. (2017). Aspectos geoeconômicos da cadeia produtiva da soja no estado de Santa Catarina: produção e circulação. Geo Uerj, (31), 745-769.

de Souza Paiva, M., Nagano, M. S., \& Hongyu, K. (2019). Análise da expansao da soja: Uma Aplicaçao de Análise Multivariada e Redes Neurais Artificiais. Sigmae, 8(2), 554-563.

de Cássia Campos, M. (2010). Expansão da soja no território nacional: O papel da demanda internacional e da demanda interna. Geografares.

Del Villar, P. M., Gameiro, A. H., \& Dabat, M. H. (2004) fatores de eficiência das culturas agrícolas no brasil: uma comparação com os Estados Unidos e França nos casos de soja, milho e arroz. Informações Econômicas, SP, v.34, n.11

Duarte, J. (2005). Entrevista em profundidade. Métodos e técnicas de pesquisa em comunicação. São Paulo: Atlas, 1, $62-83$.

Dros, J. M. (2004). Administrando os avanços da soja: Dois cenários da expansão do cultivo.

Elias, D. (2011). Agronegócio e novas regionalizações no Brasil. Revista Brasileira de Estudos Urbanos e Regionais, 13(2), 153-153.

Elias, D., \& Pequeno, R. (2007). Desigualdades socioespaciais nas cidades do agronegócio. Revista Brasileira de Estudos Urbanos e Regionais (RBEUR), $9(1), 25-39$.

Embrapa Soja (2021). Soja em números. https://www.embrapa.br/soja/cultivos/soja1/dados-economicos

Escher, F., \& Wilkinson, J. (2019). A economia política do complexo Soja-Carne Brasil-China1. Revista de Economia e Sociologia Rural, 57, 656-678.

Gazzoni, D. L. (2013). A sustentabilidade da soja no contexto do agronegócio brasileiro e mundial. Embrapa Soja-Documentos (INFOTECA-E).

Gerhardt, T. E., \& Silveira, D. T. (2009). Métodos de pesquisa. Plageder.

Gil, A. C. (2007). Como elaborar projetos de pesquisa (Vol. 4, p. 175). Atlas.

Gil, A. C. (2019). Métodos e técnicas de pesquisa social. (7a ed.), Ediitora Atlas SA.

Gillen, J. (2016). Bringing the countryside to the city: Practices and imaginations of the rural in Ho Chi Minh City, Vietnam. Urban Studies, 53(2), 324-337.

Hirakuri, M. H. (2020). O contexto econômico da produção de soja. In Seixas, C. D. S. Tecnologias de produção de soja. Embrapa Soja.

Hirakuri, M. H., \& Lazzarotto, J. J. (2014). O agronegócio da soja nos contextos mundial e brasileiro. Embrapa Soja-Documentos (INFOTECA-E).

Ibge. (2021). Cidade de Rondon do Pará. https://cidades.ibge.gov.br/brasil/pa/rondon-do-para/panorama

Lang, U. (2014). Cultivating the sustainable city: Urban agriculture policies and gardening projects in Minneapolis, Minnesota. Urban Geography, 35(4), 477485 .

Leden, L., Gårder, P., Schirokoff, A., Monterde-i-Bort, H., Johansson, C., \& Basbas, S. (2014). A sustainable city environment through child safety and mobility - a challenge based on ITS?. Accident Analysis \& Prevention, 62, 406-414.

Lima, J. G., \& da Silveira, R. L. L. (2018). Cidades médias brasileiras a partir de um novo olhar denominal e conceitual: cidades de comando regional. Desenvolvimento em Questão, 16(42), 8-41.

Marcondes, N. A. V., \& Brisola, E. M. A. (2014). Análise por triangulação de métodos: um referencial para pesquisas qualitativas. Revista Univap, 20(35), 201-208.

Martine, G., \& McGranahan, G. (2010). A transição urbana brasileira: trajetória, dificuldades e lições aprendidas. População e Cidades: subsídios para o planejamento e para as políticas sociais. Brasília: UNFPA, 11-24.

McPhearson, T., Iwaniec, D. M., \& Bai, X. (2016). Positive visions for guiding urban transformations toward sustainable futures. Current opinion in environmental sustainability, 22, 33-40.

Montoya, M. A., Bertussi, L. A., Lopes, R. L., \& Finamore, E. B. (2019). Uma nota sobre consumo energético, emissões, renda e emprego na cadeia de soja no Brasil. Revista Brasileira de Economia, 73, 345-369.

Mota, F. (2010). Folha de S.Paulo - Mortos vinham de cidade de emigrantes. https://www1.folha.uol.com.br/fsp/mundo/ft2409201023.htm

ONU (2021). Take Action for the Sustainable Development Goals. https://www.un.org/sustainabledevelopment/sustainable-development-goals/

Sanches, A. C., Michellon, E., \& Roessing, A. C. (2004). Os limites de expansão da soja. Informe GEPEC, 9(1).

Serva, M., \& Jaime Júnior, P. (1995). Observação participante pesquisa em administração: uma postura antropológica. Revista de Administração de Empresas, 35, 64-79.

Silva, M. N. D., \& Anjos, F. S. D. (2020). A expansão da soja no município de Jaguarão/RS: análise das percepções através da abordagem narrativa. Revista de Economia e Sociologia Rural, 58. 
Research, Society and Development, v. 10, n. 10, e47101018416, 2021

(CC BY 4.0) | ISSN 2525-3409 | DOI: http://dx.doi.org/10.33448/rsd-v10i10.18416

Sorj, B. (2008). Estado e classes sociais na agricultura brasileira. Centro Edelstein de Pesquisas Sociais

Steel, G., Abukashawa, S., \& Hussein, M. O. (2020). Urban Transformations and Land Governance in Peri-Urban Khartoum: The Case of Soba. Tijdschrift voor economische en sociale geografie, 111(1), 45-59.

Triviños, A. N. (1987). A pesquisa qualitativa em educação. Atlas.

Vitte, C. D. C. S. (2010). Cidadania, qualidade de vida e produção do espaço urbano: desafios para a gestão urbana e para o enfrentamento da questão social. População e cidades: subsídios para o planejamento e para as políticas sociais. Campinas: Nepo/Unicamp: Brasília: UNFPA, $1,79-97$.

Weiss, M. C., Bernardes, R. C., \& Consoni, F. L. (2017). Cidades inteligentes: casos e perspectivas para as cidades brasileiras. Revista tecnológica da Fatec americana, 5(1), 01-13.

World Bank. (2015). World Inclusive Cities Approach Paper. Report No. AUS8539.

Wolfram, M., Frantzeskaki, N., \& Maschmeyer, S. (2016). Cities, systems and sustainability: status and perspectives of research on urban transformations. Current Opinion in Environmental Sustainability, 22, 18-25.

Zedudu. (2021). MP vai fiscalizar a implantação do sistema de resíduos sólidos em Rondon do Pará. https://www.zedudu.com.br/mp-vai-fiscalizarimplantacao-do-sistema-de-residuos-solidos-em-rondon-do-para/ 